\title{
SOCIOLOGIA DA INFÂNCIA E RELAÇÕES INTERNACIONAIS:
}

\author{
diálogos possíveis \\ Childhood Sociology and INTERNATIONAL \\ RELATIONS: POSSIBLE DIALOGUES
}

Ana Cláudia Delfini C. de Oliveira ${ }^{a}$, Laís Caroline Kuss ${ }^{b}$ e Jardel Sestrem ${ }^{c}$

Resumo A infância é um fenômeno social dentro de um ordenamento social, cultural e jurídico, demarcado por categorias como socialização, gênero, classe, etnia/raça e geração. Falar em participação ou em direitos da criança, que também ocorrem dentro de um ordenamento social específico, é dar conta de um processo socialmente construído. Este artigo busca compreender como ocorre a participação social das crianças em um cenário internacional permeado pela globalização, no qual, muitas vezes, as condições de gênero, classe, geração e raça definem modos de participação infantil bastante diversificados. Seu objetivo é analisar como o tema da participação social infantil está presente nos relatórios internacionais organizados pelo UNICEF nos anos de 2003 e 2009 e da observação de referências sobre a participação infantil no meio internacional, a fim de estabelecer um diálogo entre as Relações Internacionais (RI) e a Sociologia da Infância (SI).

Palavras-chave participação infantil; meio internacional; sociologia.

\begin{abstract}
Childhood is a social phenomenon within a social order, marked by cultural and legal categories such as socialization, gender, class, ethnicity/race and generation. Talking about participation or children's rights, which also occur within a particular social order, is to realize a socially constructed process. This article seeks to understand how the social participation of children in an international scenery permeated by globalization, in which, often, the conditions of gender, class, generation and race define modes of child participation quite diverse. Its goal is

a Doutora em Sociologia pela Universidade Federal de Santa Catarina e professora dos cursos de Direito e Relações Internacionais da Univali.

b Graduanda do $7^{\circ}$ período do curso de Relações Internacionais da UnIVALI.

c Graduando do $5^{\circ}$ período do curso de Relações Internacionais da Univali.
\end{abstract}


to analyze how the issue of child social participation is presented in international reports organized by UNICEF in 2003 and 2009, and references on the observation of children's participation in international sceneries, in order to establish a dialogue between the International Relations (IR) and the Childhood Sociology.

Keywords child participation; international scenery; sociology.

\section{INTRODUÇÃO}

Nas últimas décadas, tem-se falado cada vez mais em uma proeminência das questões internacionais no cotidiano da sociedade. Apesar de fatos e decisões de alguns países, bem como sua cultura e seus problemas, influenciarem outros lugares do mundo desde o início da expansão do comércio, a partir da segunda metade do século XX, vê-se um grande aumento das Relações Internacionais e dos debates no plano internacional ${ }^{1}$. Somados a isso, a globalização do comércio e o aumento do fluxo de informações, pessoas e produtos ao redor do mundo contribuíram para a expansão da disciplina de Relações Internacionais (RI).

Nas Ciências Sociais em geral, têm-se aprofundado, também nas últimas décadas, nos estudos de gênero e infância. Nesse sentido, um ponto importante sobre os estudos na área da infância é o aparecimento de uma nova abordagem, a Sociologia da Infância (SI), que enxerga a infância como uma construção social, na medida em que acontece dentro de um ordenamento social, cultural e jurídico demarcado por categorias como socialização, gênero, classe, cultura e geração. Ao mesmo tempo, essa abordagem vê na criança um protagonista, e não um mero objeto do que acontece em sociedade.

Considerando isso, aliado ao surgimento de estudos, Organizações Internacionais Intergovernamentais (OI's) e ONG's internacionais que lidam com o tema infância, além da percepção de uma maior participação das crianças nas questões e no meio internacional, vê-se a necessidade de correlacionar as RI e a SI para

1 No Sistema Internacional, em que acontecem as relações internacionais, podem ser identificados diversos atores internacionais que definem o perfil e as transformações desse ambiente e são influenciados por ele. Até o século XX, os Estados se mantêm praticamente sozinhos como atores das relações internacionais, quando começam a surgir as Organizações Internacionais Intergovernamentais (como a ONU) e as Forças Transnacionais (como as ONG's internacionais, as Companhias Transnacionais e a opinião pública internacional. O surgimento desses novos atores gera debates acerca do grau de influência que eles têm no cenário internacional e sobre o aumento da interdependência entre os diversos fatos internacionais (Os atores internacionais. In: PeCEQuilo, Cristina Soreanu. Introdução às Relações Internacionais: temas, atores e visões. Petrópolis, RJ: Vozes, 2004). 
uma abordagem que busque na criança um protagonista do cenário internacional, que sofre as consequências e atua nos fatos internacionais.

O cenário para o desenvolvimento da SI pode ser explicado por diversos fatores associados à questão da infância, no final do século XX, como a crise social da infância (exclusão, pobreza, migração, guerra e violências que afetavam, e ainda afetam, o status social da infância e das crianças no mundo contemporâneo), além de outros, como a exposição midiática das crianças; os perfis de criança consumidora; as políticas demográficas; a institucionalização dos direitos das crianças e sua crescente participação na esfera pública; as mudanças políticas e econômicas no papel do Estado, que resultaram nas transformações dos padrões familiares do final do século $\mathrm{XX}$, etc.

Diante dessas questões, a SI, por meio do conceito de "culturas infantis"2, tem contribuído para a construção teórica e metodológica da infância no mundo contemporâneo, sobretudo em seu "berço" europeu, com estudos pioneiros na França, Inglaterra e Portugal.

Já as RI, enquanto disciplina, debatem, desde a década de 1970, a eminência de novos atores no cenário internacional, que vão além do Estado, e de novos temas que não sejam os tradicionais, como a paz e a guerra. Os chamados novos atores englobam as OI's, os movimentos internacionais, a mídia, as corporações multinacionais, os grupos terroristas, entre outros, e geram divergências nas mais diversas abordagens da disciplina quanto à relevância de seu papel no cenário internacional.

Para Sato (2005, p. 2), a emergência nas RI de temas como meio ambiente, gênero, conflitos étnico-religiosos, etc. suprime, pós Guerra-Fria, a divisão entre high politics (questões relativas à segurança e à sobrevivência dos Estados) e low politics (questões sociais e econômicas), que passaram a ser mais integradas com os novos temas. A emergência de novos temas, sobretudo no que se refere a temas mais próximos das low politics, trazem o espaço para que seja válido no âmbito das RI um estudo que mire a participação das crianças, sobretudo através de OI's e ONG’s internacionais, da mídia e de movimentos sociais, no cenário internacional.

Assim, este artigo busca compreender como ocorre a participação social das crianças em um cenário internacional permeado pela globalização, no qual, muitas vezes, as condições de gênero, classe, cultura/etnias e geração definem modos de participação infantil bastante diversificados.

2 Conceito utilizado para caracterizar "um conjunto estável de actvidades ou rotinas, artefactos, valores e idéias que as crianças produzem e partilham em interacção com seus pares” (SARMENTO, 2004, p. 373). 
O objetivo deste artigo é analisar como o tema da participação social infantil tem sido tratado nos relatórios internacionais organizados pelo $\mathrm{UNICEF}^{3}$, em especial nos anos de 2003 e 2009, bem como por meio de informações sobre a participação infantil no meio internacional e fatos internacionais que se refiram às crianças.

A metodologia embasa-se na pesquisa bibliográfica nas áreas de SI e RI e no levantamento de relatórios internacionais pesquisados nos sites do UNICEF. Na primeira parte deste artigo, apresenta-se uma revisão teórica da SI; na segunda, discute-se um panorama das RI sobre a participação infantil; e, por fim, faz-se uma análise dos relatórios do UnICEF.

\section{SOCIOLOGIA DA INFÂNCIA: NOVOS OLHARES SOBRE A INFÂNCIA}

O processo complexo de produção de saberes e representações sobre a(s) infância(s) e as crianças deve-se, em grande parte, aos estudos sociológicos sobre a infância desenvolvidos, nas duas últimas décadas do século XX, em alguns países como EUA, Portugal, França e Inglaterra (SARMEnto; Pinto, 1997; GAitán, 2006; Postman, 1999). A partir de então, o olhar sociológico sobre as infâncias mudou radicalmente com a institucionalização do campo da Sociologia da Infância (SI).

O desenvolvimento teórico-empírico da SI está ligado ao movimento do "retorno do ator"4 nas Ciências Sociais, desenvolvido nas décadas de 1960-1970, graças à influência do interacionismo simbólico, da etnometodologia e da Escola de Frankfurt. O sociólogo francês Alan Prout (2004) aponta que o surgimento das primeiras pesquisas em SI ocorreu com o desenvolvimento da Sociologia Interacionista norte-americana, cuja noção de retorno do ator foi decisiva para marcar o reencontro da criança e da infância no discurso e no campo sociológico. Todavia, foi nas décadas de 1980/1990 - décadas de grande avanço também nas legislações internacionais acerca dos direitos da criança e do adolescente como sujeitos de direitos - que houve maior desenvolvimento da SI. graças aos estudos do estruturalismo e do construtivismo social.

O revisionismo proposto por esses estudos repousava prioritariamente sobre dois conceitos essenciais da sociologia: socialização e geração. Como assinala Prout

3 O UnicEF (Fundo das Nações Unidas para a Infância) foi escolhido porque é o órgão do sistema ONU que lida com o tema da infância, e seus relatórios internacionais são fontes importantes para as análises da situação mundial da infância.

4 Para a compreensão do movimento do "retorno do ator" e das mudanças paradigmáticas efetuadas nas décadas de 1960 e 1970 acerca do caráter ativo do indivíduo, consultar as obras: de Alan Touraine. O retorno do ator. Paris: Fayard, 1984; Um novo paradigma: para compreender o mundo de hoje. Petrópolis: Vozes, 2006. 
(2004), as primeiras pesquisas da sociologia interacionista norte-americana ainda privilegiavam o tema da socialização infantil, tomando as crianças como objetos passivos de sua socialização e não como atores sociais propriamente ditos. Para se ter uma ideia do alcance desse revisionismo, destacar-se-á aqui a principal crítica da SI em relação ao tema da socialização infantil.

Conhecer a trajetória histórica dos comportamentos e das formas de ser e de pensar sobre a(s) criança(s) possibilita desconstruir a ideia de uma natureza ou essência infantil idealizada e universal, tão difundidas pela pedagogia e filosofia do século XIX, ciências com as quais a sociologia da educação, e principalmente Emile Durkheim, tinham um grande comprometimento. Ora, essas ciências elaboram um discurso monopolizador sobre a infância, desde, pelo menos, o século XVIII, como propunha o discurso iluminista e seu projeto racionalista que dominava o debate pedagógico acerca das teorias da competência e os discursos sobre a socialização, o cuidado e a educação das crianças.

A própria sociologia tinha uma compreensão equivocada do processo de socialização infantil e não considerava que as crianças pudessem ter uma participação social relevante ou significativa para a sociedade, ou seja, as crianças não tinham nada a dizer ou com o que colaborar com sua sociedade. A tradição sociológica, que remonta aos estudos de Durkheim (2002, p. 21) ${ }^{5}$, entendia que a socialização das crianças ocorria de modo passivo e por imitação do estilo de vida dos adultos, ou seja, ela era entendida apenas como um processo de integração entre as gerações, caracterizado, de um lado, pela ação dos adultos e das instituições sociais sobre as crianças e, de outro, pela apropriação desse processo pela ação passiva das crianças.

A SI vem justamente problematizar essa visão adultocêntrica da socialização, na tentativa de superar a ideia de passividade infantil. Em decorrência, questiona a institucionalização como condição-chave para que a criança se socialize, principalmente em relação ao papel hierárquico e autoritário das instituições como a família e a escola. Sem a pretensão de ser exaustivo nessa discussão, aponta-se que a SI lançou novas abordagens sobre a socialização infantil. Isso não significa que a SI tenha abandonado a teoria da socialização, ao contrário, ela foi reinterpretada à luz das discussões que recuperam a capacidade de agência e controle da criança durante sua socialização e como isso pode influenciar na própria sociedade.

5 Na obra Educação e sociedade, que reúne os principais ensaios de Durkheim sobre o tema, este fala dos humores das crianças em sua discussão sobre o entroncamento da educação e da moral, que resulta nos três elementos principais da educação moral das crianças e/ou, das novas gerações - o espírito de disciplina, o espírito de abnegação e o espírito de autonomia (DuRKHEIM, 2002, p. 21) 
O interesse da SI está, antes de mais nada, no estudo da própria sociedade por intermédio do entendimento da infância como categoria geracional, ou seja, a infância é uma categoria explicativa da sociedade justamente porque ela se insere na trama das relações entre as gerações. Em outro trabalho, Sarmento (2005, p. 18) reafirma que o sentido da SI reside na compreensão da sociedade a partir do fenômeno social da infância, isto é, ao observar a infância como categoria geracional, a SI colabora na superação da própria sociologia como ciência "adultocêntrica", desatenta ao universo infantil e às crianças como sujeitos ativos, cujos pontos de vista eram ignorados ou secundarizados nas pesquisas. Antes consideradas como simples apêndice da sociedade dos adultos, a SI trouxe a preocupação de pensar as crianças como interlocutoras centrais nas pesquisas sociológicas, e a infância, como uma construção social do tipo geracional, cujos contextos e problemas levam à compreensão de diferentes infâncias vividas por diferentes crianças.

Assim, a sociologia descobriu novas maneiras de pensar as infâncias e as crianças, graças aos debates ocorridos em vários congressos europeus que ajudaram na criação da rede de estudos "Criança e Sociedade", além de várias obras e revistas científicas, entre elas a de Chris Jenks, The Sociology of Childhood: essential readings, publicada sem muito alarde em 1982 e reeditada com sucesso em 1992. Nessa reedição o autor comenta o sucesso de sua obra ao dizer que alguma coisa mudou em relação "à nossa percepção colectiva da infância durante aquela década” (Jenks apud Christensen; Allison, 2005, p. 58).

E mudou mesmo. Desde 1990, diversos cientistas sociais têm se ocupado com o tema da infância, a partir de novos paradigmas, reinventando olhares e metodologias próprias, que convém investigar, a fim de avaliar os alcances e limites dessas novas leituras sobre a infância para que se possa compreender o papel da(s) criança(s) e da(s) infância(s) na sociedade atual.

O que praticamente todos(as) os(as) autores(as) da SI, em suas mais diversas correntes, querem transmitir é que seu objetivo é conhecer o mundo infantil por intermédio do que as crianças têm para mostrar e ensinar e que, para isso, é preciso ouvi-las e tratá-las como atores sociais capazes de construir seu próprio mundo, de acordo com o modo como estruturam e são estruturadas pelas condições de classe social, raça/etnia, gênero e geração à qual pertencem. Desse modo, é unívoco afirmar que a SI procura libertar a ideia de infância das perspectivas biologizantes que tendem a interpretar as crianças como indivíduos pré-sociais que se desenvolvem independentemente do contexto onde vivem.

E é exatamente nesse ponto que se cruzam os interesses teóricos e empíricos da SI e das RI, uma vez que é possível construir o diálogo dessas áreas a partir do 
mesmo objetivo aqui discutido. Diante disso, Régine Sirota (2001, p. 11) colabora para esse debate com a realização de um balanço das principais contribuições da SI a partir de sua síntese:

1. A criança é uma construção social. A infância é compreendida como uma construção social. 2. As crianças devem ser consideradas como atores em sentido pleno e não simplesmente como seres em devir. 3. As crianças são ao mesmo tempo produtos e atores dos processos sociais. Trata-se de inverter a proposição clássica, não de discutir sobre o que produzem a escola, a família ou o Estado, mas de indagar sobre o que a criança cria na intersecção de suas instâncias de socialização. [...] 4. A infância é uma variável da análise sociológica que se deve considerar em sentido pleno articulando-a às variáveis clássicas como a classe social, o gênero, ou o pertencimento étnico.

É por tudo isso que, para pensar a infância hoje, torna-se necessário um olhar cada vez mais interdisciplinar e é neste sentido que um diálogo com os estudos das RI torna-se tão útil. Se esse campo ainda não dialoga com a infância e as crianças como a sociologia tem feito, no sentido de construir categorias ou teorias de análise, ao menos é possível perceber como os relatórios, os documentos de organizações internacionais e as análises de fatos internacionais têm tratado o tema. Em outras palavras, quer-se investigar como eles têm chamado a atenção para a participação das crianças nos cenários onde estão localizadas, como têm interpretado a participação social infantil, se predomina uma cultura "adultocêntrica" que ainda trata as crianças e o universo infantil apenas como o mundo dos "não adultos" e, ainda, se é possível perceber a incorporação nos relatórios internacionais das discussões teóricas mais recentes sobre o papel da infância e da participação infantil.

\section{RELAÇÕES INTERNACIONAIS: UM PANORAMA DO OLHAR DA DISCIPLINA SOBRE AS CRIANÇAS}

A disciplina de Relações Internacionais (RI) ainda é considerada muito jovem. Data do início do século XX e tem seu marco com a publicação do livro de E. H. Carr, Vinte anos de crise: 1919-1939. Uma introdução ao estudo das relações internacionais, no período entre a Primeira e a Segunda Guerras Mundiais. Até o final do século XX, as RI consideravam como os chamados "atores internacionais" aqueles que influenciam e sofrem influência dos "fatos internacionais", somente os Estados. Com a crescente participação das Organizações Internacionais Inter- 
governamentais (OI's), das Organizações Não Governamentais Internacionais (ONG’s), dos Movimentos Sociais internacionais e das Corporações Multinacionais no "Cenário Internacional", diversos autores das RI passaram a considerar também estes como atores internacionais, e, portanto, suas relações passaram a ser abarcadas pelos estudos das RI (PECEQuilo, 2004).

Apesar disso, a discussão acerca dos atores das RI ainda não foi encerrada, e hoje, a partir da crescente interação entre os indivíduos de diversos Estados e sua participação como “opinião pública internacional”, questiona-se a participação do indivíduo como ator internacional, que sofre e influencia os fatos do cenário internacional.

Os principais temas das RI também passam por um intenso debate, já que, a princípio, a disciplina investigava apenas relações que envolviam o chamado hard power e as high politics (questões de segurança nacional, poder militar, etc.) e hoje investiga também questões ligadas ao que se chama de soft power e low politics (questões de cultura, ideologia, diplomacia, de gênero, meio ambiente, etc). É nesse debate que se insere a discussão sobre o papel das crianças nas relações internacionais, ou seja, como elas participam dos fatos internacionais onde estão presentes.

Nas RI, os temas de high politics ou de hard power sempre estiveram à frente dos principais assuntos, e isso fez com que, quase sempre, as RI relegassem a um segundo plano temas que concernem, por exemplo, aos direitos humanos, ao meio ambiente, às mulheres e àqueles relacionados à infância. Apesar disso, as crianças sofrem e influenciam, de certa forma, aquilo que acontece no cenário internacional e são alvo também das ações dos atores que nele atuam, como no caso das guerras ou dos estudos no nível internacional (com ONG's, OI's ou movimentos sociais que procuram dar ênfase às crianças). É pelo fato de a criança (apesar dos avanços ocorridos no Direito Internacional a favor de seus direitos e da maior visibilidade alcançada) ser deixada de lado pelas RI que os tópicos a seguir - acerca do contexto histórico e dos fatos internacionais - procuram dar maior ênfase ao questionamento: onde podem ser encontradas as crianças nas Relações Internacionais?

\section{CONTEXTO HISTÓRICO-JURÍDICO INTERNACIONAL}

Para estreitar a relação entre a SI e as RI, cumpre observar um pouco do contexto histórico internacional acerca da infância, nos últimos decênios do século XX. Os primeiros congressos dedicados ao tema da infância aconteceram na Antuérpia, Bélgica, em 1894; em Bruxelas, em 1895; e em Liège e Paris, no ano de 1905. 
Em Paris, nesse mesmo ano, também ocorreu o Primeiro Congresso Internacional de Gotas de Leite; o segundo foi em Bruxelas, em 1907, quando então foi criada a União Internacional de Proteção à Infância da Primeira Idade; e o terceiro foi realizado em Berlim, em 1911. Em 1913, foi a vez do Primeiro Congresso de Proteção à Infância, na Bélgica. Os congressos americanos foram organizados a partir de 1916, por ocasião do centenário da independência dos países da América do Sul. O primeiro congresso ocorreu em 1916, em Buenos Aires; o segundo foi em 1919, em Montevidéu; o terceiro no Brasil em 1922; o quarto em Santiago do Chile, em 1924, quando foi aprovado o estatuto de criação do Instituto Internacional Americano de Assistência e Proteção à Infância (IIN), cuja data oficial de criação foi em 1926, com a adesão dos países: Argentina, Bolívia, Brasil, Chile, Cuba, Equador, Estados Unidos, Peru, Uruguai e Venezuela. O INN, atualmente, é o Instituto Interamericano da Criança e do Adolescente, pertencente à OEA - Organização dos Estados Americanos. A data do quinto congresso não foi possível de ser localizada na literatura pesquisada. Por fim, o sexto congresso foi realizado no Peru, em 1930. Todos esses congressos tiveram um forte apelo pan-americanista, como é o caso da definição da data de 12 de outubro como o Dia da Criança, deliberada no Terceiro Congresso Americano da Criança, em referência às festas da criança pobre realizadas por Moncorvo Filho. A proposta, encaminhada por Almir Madeira, do Instituto de Proteção e Assistência à Infância de Niterói, sugeria uma referência dessa data à comemoração da descoberta da América, em nome da fraternidade americana entre os Estados no "Novo Continente" (Kuhlmann JR., 2001, p. 156).

Como resultado desses congressos, foram criadas diversas instituições, a exemplo da Union for the Protection of Infant Life, em 1900; a Association Internationale pour la Protection de l'Enfance, em 1921, na Bélgica; a British National Association of the Prevention of Infant Mortality, de 1913; a Save the Children International Union, em 1919/1920, na Inglaterra; a International Union for Child Welfare ou Union Internationale de Protection de l'Enfance, em 1910, na Suíça. (Nunes; Carvalho, 2008, p. 4).

A discussão sobre a proteção especial das crianças teve início no começo do século XX, em várias cidades, como Paris, Bruxelas e Washington, nas quais surgiram as organizações para o bem-estar da criança, como a Children's Bureau, nos EUA (1912), a Associação Internacional para a Proteção da Infância (1913), o Comitê para a Proteção da Infância da Sociedade das Nações (1919); e a União Internacional para a Proteção da Criança, que, em 1923, editou a Declaração de Genebra, promulgada pela Assembleia da Sociedade da Nações, em 1924, que, entre outras coisas, afirmou o princípio da proteção especial à infância. Essa declaração, 
encabeçada pela ONG Save the Children (1919), é considerada o primeiro documento norteador das declarações seguintes: a Declaração Universal dos Direitos das Crianças (1959), tendo como base os direitos à liberdade, ao estudo, a brincar e ao convívio social, preconizados em seus dez princípios, e a Convenção dos Direitos da Criança de 1989 (FonseCA, 2004, p. 106).

Essa Convenção teve como meta principal a regulamentação, em seus 54 artigos, dos direitos de proteção, provisão e participação das crianças, bem como incentivar os países membros a implementar o desenvolvimento pleno e harmônico das crianças como seres em desenvolvimento e na condição de "sujeitos de direitos". Ela caracteriza bem as questões que envolvem a condição social da infância, ao final da década de 1980, como, por exemplo, a discriminação (art. 2), nacionalidade e identidade (art. 7 e 8), a situação das crianças refugiadas e o direito de reencontrar a família (art. 22 e 10), direito à intimidade (art. 16), proteção contra exploração e tortura (art. 36 e 37) e o direito à liberdade de opinião e participação social, preconizado nos artigos 12, 13 e 15 da Convenção.

No andamento da pesquisa, foi possível observar que, historicamente, o tema da proteção social da criança evoluiu para o tema do direito da participação social da criança em seus mais diversos contextos. Isso não significa dizer que o tema da proteção perdeu sua ênfase, mas que ele se alia ao tema da participação, uma vez que há a ideia de que uma infância protegida pode ser mais participativa e protagonista do que uma infância vulnerável. É o que inferem os documentos que serão discutidos. Por exemplo, sobre o direito de participação social da criança no cenário europeu, Natália Fernandes Soares (2002) mostra como os documentos internacionais elaborados na Convenção Europeia para o Exercício dos Direitos da Criança (1996) dispõem sobre o tema da participação infantil na Recomendação 1.286 da Assembleia Parlamentar do Conselho da Europa, que define uma Estratégia Europeia para as crianças nos seguintes termos:

Sendo as crianças cidadãos da sociedade de hoje e de amanhã, o respeito pelos seus direitos e uma maior igualdade entre crianças e adultos deverão ser salvaguardados, de forma a preservar o pacto entre gerações e a contribuir para a democracia. Para tal, propõe uma intervenção, no âmbito do Comité de Ministros, no sentido de "[...] fazer com que as perspectivas das crianças sejam tidas em conta na tomada de decisões que as afectam, e facilitar a sua participação activamente, responsavelmente e de uma forma apropriada às suas capacidades, na escola e outras instituições, em procedimentos judiciais e nos governos nacionais (alínea ii)”, e ainda “[...] ensinar as crianças a agirem como cidadãos 
responsáveis, encorajá-las a terem interesse nos assuntos públicos e a reconsiderar a idade de voto" (alínea iii, Recomendação 1.286).

O documento expressa claramente a incorporação dos paradigmas da SI tanto no que se refere à percepção dos pontos de vista e decisões das crianças sobre aquilo que as afeta quanto no incentivo à participação responsável e adequada das crianças não apenas nas escolas, mas em espaços não usuais, onde essa participação ainda não é totalmente vivenciada, como nas audiências e nos procedimentos judiciais e nos governos locais e/ou nacionais. O tema da proteção é tratado subjetivamente na frase que expressa o princípio universal de que "as crianças são cidadãos de hoje e de amanhã”, pressupondo, com isso, que todas as crianças estão adequadamente protegidas e em dia com sua cidadania.

Outra autora que se destaca nesse tema é Raquel Rei (2006), em sua pesquisa sobre a participação social das crianças no cenário internacional. Ela mostra os avanços na compreensão jurídica da participação infantil presente nos tratados internacionais, como a Convenção dos Direitos da Criança, por ela reiterados da seguinte forma:

O direito a ser ouvido e a que as suas opiniões sejam tidas em conta - em função da sua idade e da sua maturidade com o maior ou menor peso - é um dos direitos mais inovadores incluídos na Convenção dos Direitos da Criança. O próprio Comitê dos Direitos da Criança, encarregado de zelar pelo cumprimento e pela interpretação do estabelecido na Convenção, ressaltou nas mais variadas ocasiões que o direito à participação é um dos quatro pilares da Convenção.

No entanto, o binômio proteção-participação aparece em um questionamento da autora, ao indagar sobre até que ponto as crianças são tratadas, em suas sociedades e pelos próprios organismos internacionais, como sujeitos de direitos e "como um todo integral, não fragmentado", avaliando se de fato rompeu-se "com as políticas que actuam como compartimentos estanques e que não têm em conta as necessidades da infância já que todas se inter-relacionam” (REI, 2006, p. 5). Segundo Rei (2006, p. 5), o direito à participação social da infância supõe:

O reconhecimento de que este sector da população goza de uma certa capacidade genérica para participar. No entanto, esta capacidade genérica, para fazer-se realmente efectiva, deve desenvolver-se. Deste modo, é necessário não só admitir o direito a participar, mas também a formar os indivíduos para que possam 
exercê-lo eficazmente. [...] No entanto, não basta o simples facto de reconhecer e incorporar esses direitos nas legislações dos países membros da Convenção, mas fazer uma política proactiva no que respeita a esses direitos. Isto é, cada Estado deve levar a cabo diversas actividades para que os chamados "direitos da autonomia" passem da retórica à realidade (grifo nosso).

Portanto, para a participação real e efetiva, implica-se que haja pelo menos três grandes condições que foram destacadas nesses documentos: 1) Reconhecimento do direito a participar, que envolve, necessariamente, uma consciência de cidadania; 2) Disposição das capacidades necessárias para exercê-lo, ou seja, competências, conhecimento, capacidade crítica, destrezas, habilidades, atitudes e valores que ajudam a formar as competências participativas; e 3) meios ou espaços idôneos para participação, como a família, a escola, e outras instituições educativas, constituindo esses os âmbitos mais imediatos e próximos para a participação infantil.

\section{FATOS INTERNACIONAIS CARACTERIZADOS PELA PARTICIPAÇÃO INFANTIL}

A criança nunca foi o centro da agenda das RI. Apesar de os fatos internacionais muitas vezes terem crianças envolvidas, pela participação ativa ou passiva, há grande dificuldade de encontrar estudos no sentido de desvendar qual a forma de participação das crianças nos fatos internacionais. No entanto, a revisão de literatura efetuada para este artigo aponta para três cenários de participação infantil:

1) As crianças e os conflitos talvez sejam o tema mais presente entre as RI e a infância. Diante de conflitos, as crianças são afetadas e, por vezes, participam ativamente deles, como no caso das crianças-soldado ${ }^{6}$, que geralmente são obrigadas a participar deles e, quando não acabam mortas, ficam traumatizadas. Uma das maneiras de participação das crianças nas guerras $^{7}$ acontece quando elas se tornam órfãs, pois seus pais são vítimas

6 Exemplo atual da participação de crianças-soldado pode ser visto no conflito separatista entre Sudão e Sudão do Sul: GreEn, Andrew. Como devolver a infância às crianças-soldado. Disponível em: <http://envolverde.com.br/noticias/como-devolver-a-infancia-as-criancas-soldado/>. Acesso em: 01/05/2012 e também nos protestos de 2011 contra o governo do Iemen: KAMALDIEN, Yazeed. Crianças aprisionadas no coração do levante. Disponível em: <http://envolverde.com. $\mathrm{br} / \mathrm{ips} /$ inter-press-service-reportagens/criancas-aprisionadas-no-coracao-do-levante-2/>. Acesso em: 01/05/2012.

7 O termo "guerra" aqui é tido como o conflito internacional, quando as "guerras civis" são tratadas como conflitos civis. 
ou vão à guerra. Outras vezes, essas crianças se tornam também refugiadas, em países desconhecidos ${ }^{8}$. Sofrer as consequências dos conflitos é a forma mais comum de participação, das quais se pode identificar uma forma passiva em que as crianças não participam ativamente das decisões que envolvem os conflitos. Nos conflitos que envolvem Israel e Palestina, tem-se ainda o caso de crianças que são "processadas nas cortes militares israelenses depois de presas, interrogadas e detidas", segundo relatório do DCI-Palestina (Defense for Children International), ao mostrar que, por ano, cerca de 700 crianças da Cisjordânia são processadas nas cortes militares israelenses 9 .

2) A adoção internacional é outro fato internacional que conta com a participação passiva de crianças, além do sequestro internacional de crianças e do tráfico infantil internacional ${ }^{10}$, nos quais as crianças, geralmente de países subdesenvolvidos, são enviadas a países desenvolvidos, trocadas como mercadorias, muitas vezes para trabalhar quase de forma escrava. Também os divórcios em famílias compostas por pais e mães de nacionalidades diferentes trazem consequências diretas na vida de crianças, as quais frequentemente sofrem uma disputa entre as famílias por sua guarda, diante da Justiça internacional ${ }^{11}$.

3) Também é possível perceber a emergência de um crescente veículo de informações e participação das crianças no cenário internacional com as organizações internacionais que se especializam em causas a favor das crianças. Nesse sentido, destacam-se os trabalhos da Save the Children, que foi apontada por um ranking publicado pelo Global Journal como a $18^{\mathrm{a}}$ entre as 100 melhores ONG's do mundo. Outro destaque é o UNICEF (Fundo das Nações Unidas para a Infância), além de ONG's ainda pouco

8 Mais informações sobre crianças refugiadas e a adoção internacional podem ser encontradas no artigo: "A excepcionalidade da adoção internacional”, de Rebeca Marchesoni Salles Oliveira, apresentado como trabalho de conclusão de curso da autora, na Universidade do Vale do Itajaí, no segundo semestre de 2011.

9 Hartmann, Arturo. Oriente Médio: infância entre grades: Disponível em: <http://ponto.outraspalavras.net/2011/10/25/infancia-entre-grades-criancas-palestinas-sao-alvo-de-tortura-detencoes-ilegais-em-israel/>. Acesso em: 26/10/2011.

10 Algumas outras informações sobre o tráfico internacional de menores em: Deutsche Welle. Tráfico de crianças é problema global. Disponível em: <http://www.dw.de/dw/article/o,,1036172,00. html>. Acesso em: 23/03/2012.

11 Caso de grande repercussão nesse sentido foi o do menino Sean Goldman. Ver: Caso Sean Goldman: garoto fala pela $1^{\mathrm{a}}$ vez à TV nos EUA. Disponível em: <http://veja.abril.com.br/noticia/internacional/caso-sean-goldman-garoto-fala-pela-1a-vez-a-tv-americana >. Acesso em: 01/05/2012. A Convenção da Haia sobre os Aspectos Civis do Sequestro Internacional de Crianças traz os aspectos e as normas internacionais que regulam essa questão e pode ser encontrada em: <http://www.planalto.gov.br/ccivil_o3/decreto/D3413.htm>. Acesso em: 23/03/2012. 
comentadas popularmente, como a Defence for Children International, a Friends International e a Free the Children. A Defence for Children possui membros associados em 30 países e mais de 30 anos de luta pela defesa dos direitos da criança ${ }^{12}$. Já a Friends International foi criada em 1994 e se dedica a projetos voltados à assistência de crianças e jovens de rua, órfãos, migrantes, dependentes químicos e profissionais do sexo, hoje no sudoeste asiático e em Honduras, México e Egito ${ }^{13}$. Talvez a organização que mais chame a atenção seja a Free the Children, pois é composta por crianças que acreditam ter o poder de afetar positivamente o mundo, não se limitando a uma participação passiva, mas atuando por meio de uma participação ativa e consciente. Essa organização foi fundada em 1995 por um garoto de 12 anos e hoje é um movimento que conta com mais de 1 milhão de crianças, de 45 países, no combate à pobreza e à exploração. ${ }^{14}$

Ainda no âmbito das organizações internacionais, pode-se enxergar uma maior abertura diante da participação das crianças em conferências, como a RIO $92^{15}$, o III Congresso Mundial sobre os Direitos das Crianças e Adolescentes, ocorrido em Barcelona, no ano de 2007, no qual a participação efetiva das crianças está implícita na elaboração do documento "Declaração de Barcelona”. Havia, em Barcelona, um Fórum de adultos e um de crianças, que seguiam as temáticas: pobreza, saúde, educação, trabalho, violência e exploração. Diante desses trabalhos, apresentaram-se a produção de um retrato da situação infantil e a Declaração de Barcelona. Participaram do Congresso 300 crianças (REI, 2006, p. 8). Outro exemplo recente é a "Agenda da Infância 2012-2015", um documento apresentado pela ONG Save the Children ao governo da Espanha, que seria eleito pouco tempo depois do lançamento da proposta, e também aos partidos políticos, deputados e outras instituições governamentais da Espanha. Esse documento tem como objetivo renovar o compromisso do governo espanhol com os direitos das crianças,

12 The DCI Movement. Disponível em: <http://www.defenceforchildren.org/about-us.html>. Acesso em: 30/04/2012.

13 The Global Journal. Friends international. Disponível em: <http://theglobaljournal.net/article/ view/557/>. Acesso em: 30/04/2012.

14 The Global Journal. Free the children. Disponível em: <http://theglobaljournal.net/article/ view/564/>. Acesso em: 30/04/2012.

15 Na Rio 92, Conferência das Nações Unidas para o Meio Ambiente e o Desenvolvimento, promovida em 1992, a menina Severn Suzuki, de 12 anos, da Organização das Crianças em Defesa do Meio Ambiente, falou aos representantes dos Estados, em um discurso que impressionou o mundo. Nobrega, Camila. Severn Suzuki, a menina que calou o mundo na Rio 92. Disponível em: <http://oglobo.globo.com/rio2o/severn-suzuki-menina-que-calou-mundo-na-rio-92-4638046>. Acesso em: 01/05/2012. 
considerando-as seres humanos do presente, com direito a ter voz e participar das decisões que as $\operatorname{afetam}^{16}$.

Também são as organizações e os estudos internacionais sobre a infância que costumam dar maior atenção aos condicionamentos de raça, gênero, geração, etc., como se pode ver nos relatórios e declarações internacionais publicados nesses âmbitos. Resumidamente, pode-se perceber que o protagonismo infantil é muito enfatizado nos documentos e fatos internacionais aqui analisados que discutem o tema da participação social infantil a partir dos contextos locais onde as crianças estão inseridas, em especial das situações de violação de seus direitos, porém os fatos internacionais não dão visibilidade para as discussões teóricas, que serão observadas nos relatórios do UnICEF, que se dedicou a esse tema nos anos de 2003 e 2009.

\section{RELATÓRIOS UNICEF E A PARTICIPAÇÃO INFANTIL}

O UniceF publica periodicamente informes e relatórios que circulam mundialmente (onde essa organização está presente) sobre a situação das crianças no mundo ou em determinadas regiões. Essas informações fornecem dados no plano mundial e um panorama de como as crianças são vistas por organizações centrais para o debate contemporâneo acerca da infância. Os relatórios UNICEF são edições anuais que abordam os mais diversos temas envolvendo a situação mundial da infância, de modo que, a partir do levantamento aqui realizado, decidiu-se por um recorte temporal dos anos 2003 e 2009, visto que a participação social infantil é tratada em especial nesses dois anos ${ }^{17}$.

16 Como exemplo, cita-se a recente decisão do governo espanhol, em seu compromisso pela infância consciente, ao aprovar o Protocolo Facultativo de la Convención sobre los Derechos del Niño de Naciones Unidas, no dia 24 de fevereiro de 2012, pelo qual "cualquier niño o niña podrá presentar una queja frente a cualquier violación de sus derechos y obtener respaldo legal. La firma, que tendrá lugar em el 28 de febrero en la sede del Consejo de Derechos Humanos de la ONU em Ginebra es 'un primer gesto simbólico muy importante y con él España reafirma su compromiso con los derechos de la infancia. Ahora este gesto tiene que completarse con la ratificación en el Parlamento y además, España debe animar a otros Estados a que firmen y ratifiquen también', explica Yolanda Román, responsable de Incidencia Política de Save the Children". Save the children. Agenda de infância 2012-2015. Disponível em: <http://www. savethechildren.es/docs/Ficheros/465/Agenda_de_Infancia_2012-2015.pdf >. Acesso em: 05/06/2012.

17 A título de informação, em 2004, o relatório do Unicef focalizou a educação de meninas (que merece um estudo à parte, pois é necessário ao internacionalista avaliar como as relações de gênero e infância estão sendo construídas pelo UNICEF); em 2005, discutiu a questão de crianças ameaçadas pelas adversidades; já o relatório de 2006 trouxe as crianças excluídas e invisíveis; em 2007 o relatório abrangeu a questão das mulheres e crianças e levantou um discurso sobre as questões de gênero; e em 2008 tratou especificamente da sobrevivência infantil, sem abordar aspectos relacionados ao tema em tela. 
A questão principal desta análise foi: é possível falar em uma participação social das crianças no cenário de forte globalização, onde parece predominar uma cultura juvenil e "adultocêntrica"? Para respondê-la, foram analisados os relatórios em dois momentos: em primeiro lugar, a partir da discussão teórica da SI, em especial a discussão dos conceitos de socialização e participação e na revisão dos paradigmas da SI, considerando as crianças como atores sociais e a infância como construção social. Em segundo lugar, foram analisados os cenários internacionais tratados nos relatórios e o posicionamento do UNICEF em relação ao tema da participação social infantil em um cenário onde muito se fala em "infância global" e pouco se fala em infâncias marcadas por questões culturais (sobretudo as de gênero), econômicas, políticas e sociais muito distintas.

\section{SITUAÇÃO MUNDIAL DA INFÂNCIA: PARTICIPAÇÃO INFANTIL (2003)}

O relatório abre com o seguinte título: “Crianças devem ser ouvidas” e descreve a seguinte situação, que ressalta a importância da participação social das crianças (UNICEF, 2003, p. 1):

Os adultos não percebem. Quando é que uma criança é considerada suficientemente capacitada para contribuir e participar ativamente? Se você não lhes der a oportunidade de participar, elas não desenvolverão as habilidades. Dê-nos uma chance cedo e veja como vamos voar. Khairul Azri, 17 anos de idade, delegada malaia na Sessão Especial das Nações Unidas sobre a Criança. Quando a chinesa Mingyu Liao, de 10 anos de idade, fez sua apresentação no Encontro Mundial de Cúpula sobre Desenvolvimento Sustentável em Joanesburgo, na África do Sul, em setembro de 2002, fazia parte do grupo de três representantes da Conferência Internacional das Crianças do Programa de Meio Ambiente das Nações Unidas, que três meses antes havia reunido mais de 400 crianças de mais de 80 países. “Todos nós tínhamos muita coisa a dizer", relatou a menina, "mas a principal, que preocupava todos os delegados, é que a maioria dos líderes não ouve”. [...] Era impossível negar o que diziam os jovens ativistas. Com sua visão do futuro e sua paixão, motivaram delegados como outros já haviam feito na Sessão Especial das Nações Unidas sobre a Criança, em maio de 2002. "Pensem nas crianças," eles pediram. "Que tipo de mundo vocês querem para elas?” No final, as crianças conseguiram algo que não havia sido possível alcançar pelos processos de negociação usuais dos adultos com relação à declaração final do Encontro de Cúpula. Líderes mundiais reconheceram que tinham responsabilidades não 
só com relação uns aos outros, mas com relação às crianças - uma vez que elas pediram que libertassem o mundo da pobreza, da degradação ambiental e de padrões de desenvolvimento insustentável (grifo nosso).

O parágrafo expressa bem o teor do relatório, ao incentivar a participação social e política das crianças. Todavia, qual o conceito de participação presente no relatório? Para a UnICEF (2003, p. 4), participação é:

\begin{abstract}
Um fenômeno multifacetado que inclui uma ampla variedade de atividades que diferem na forma e no estilo conforme a idade da criança: buscando informações, manifestando desejo de aprender, mesmo com muito pouca idade, estruturando opiniões, expressando idéias; participando de atividades e processos; sendo informada e consultada em tomadas de decisões; colocando em ação idéias, processos, propostas e projetos; analisando situações e fazendo escolhas; respeitando as outras pessoas e sendo tratada com dignidade.
\end{abstract}

Esse conceito, que traz em seu bojo um resumo dos artigos da Convenção, orienta as ações descritas no relatório, o qual mostra como a participação social infantil geralmente se restringe ao espaço familiar e escolar, mas que, com o auxílio de organizações como UnICEF, ampliam-se dos espaços privados para espaços públicos, alcançando influência global. O relatório é exaustivo em exemplos mostrando que o UNICEF tem promovido e implantado escolas genuinamente amigas das crianças, com métodos que maximizam a participação da criança e que estimulam a aprendizagem ativa, em vez da apreensão passiva dos fatos. Cita as "escuelas nuevas" na América Latina, que utilizam uma nova metodologia de impacto direto na participação e no comportamento democrático de seus alunos dentro da comunidade.

As organizações que ouvem as crianças também são relatadas e incluem as crianças como parte da delegação que, junto ao governo, trabalha na construção de políticas para as crianças. Também são apresentadas crianças atuantes na ONU, como ocorrido em 2002 na Assembleia Geral, quando as crianças participaram diretamente na Sessão Especial sobre a criança.

Nesse relatório, é possível falar em uma participação social e política das crianças no cenário de forte globalização, apesar da cultura juvenil e "adultocêntrica" que marca o mundo atual. O próprio relatório chama os adultos à responsabilidade de "buscar as perspectivas e as opiniões de crianças e de levá-las a sério; e na responsabilidade dos adultos de ajudar crianças e adolescentes 
a desenvolver suas competências para que tenham uma participação autêntica e significativa no mundo" (UNICEF, 2003, p. 2). Fica explícito o entendimento do relatório acerca da necessidade de se revisar o olhar internacional sobre as crianças, de levá-las a sério de forma teórica e empírica, como propõe a SI.

Em relação aos paradigmas da SI, o relatório reconhece a infância como uma construção social dentro de um ordenamento social, cultural e jurídico específico, no qual as condições de gênero ${ }^{18}$, classe, geração e raça sempre estão presentes, porém ainda sobressai a perspectiva do adulto induzindo a criança no caminho por ele traçado previamente, como observa-se a seguir:

Precisamos aprender como efetivamente induzir crianças e jovens a manifestar suas opiniões, e precisamos aprender a reconhecer suas múltiplas vozes, as diversas maneiras pelas quais crianças e jovens se expressam, e como interpretar suas mensagens - verbais e não verbais. E mais importante, devemos garantir que existam oportunidades, tempo e locais seguros para que as opiniões de crianças e jovens sejam ouvidas e consideradas devidamente (UNICEF, 2003, p. 2, grifo nosso).

Se há mudanças significativas na situação de vulnerabilidade em que se encontram as crianças, por condições de classe, gênero e/ou raça, deve-se mais à ação direta do UNICEF em "induzir e garantir" os espaços e as falas das crianças do que propriamente por uma organização espontânea das próprias crianças envolvidas

18 Sobre as relações de gênero, o relatório aponta para as vantagens econômicas e sociais da educação das meninas: "Organizações de desenvolvimento de todos as proporções há muito concordaram sobre as vantagens em termos de relação custo-benefício dos investimentos na educação de meninas, e sobre a necessidade urgente de promover essa educação, especialmente nos países africanos ao sul do Saara e na Ásia Meridional, onde mais de 50 milhões de meninas em idade escolar estão fora da escola. Entretanto, quando foi lançado em Uganda, em agosto de 2001, o Movimento de Educação de Meninas (MEM) mostrou ser diferente dos esforços anteriores, uma vez que as próprias crianças e os adolescentes africanos - meninos e meninas - assumiram a liderança, contando com a experiência e o conselho dos adultos quando necessário, e envolvendo-se no movimento com sua própria dedicação e seu otimismo. A própria participação das crianças foi educativa: as jovens quenianas e ugandenses que participaram do MEM desde seu início, inclusive algumas portadoras de deficiências, foram treinadas em métodos de facilitação criativos. Isso permitiu que realizassem oficinas semelhantes na África do Sul e em Zâmbia para difundir as informações na comunicação apresentada no Parlamento de Crianças e Jovens em Kampala. 'Essa conferência foi um divisor de águas para muitas jovens que no início não podiam dizer nada', disse Caroline, uma estudante ugandense voluntária. 'Nós desenvolvemos assertividade e confiança, e começamos a pensar positivamente sobre nossas capacidades.' [...] E mais, quando o domínio masculino tradicional se abre e permite que meninas e jovens mulheres participem, rompem-se os estereótipos de meninas e mulheres como figuras ornamentais ou pessoas mais fracas do que os meninos - tanto física quanto emocionalmente" (UNICEF, 2003, p. 30). 
ou pelo interesse dos governos e entidades locais. Diante disso, o relatório não reconhece uma cultura infantil própria das crianças, como discute a SI.

Em termos de cenários internacionais, foram incluídas nesse relatório as crianças de diversos contextos sociais, porém é dada uma ênfase maior nas crianças de países subdesenvolvidos, como, por exemplo, adolescentes na África que atuam como educadores combatendo o HIV/Aıds; no Paquistão, meninas entre 11 e 17 anos, especialmente aquelas de famílias de baixa renda, que participam de oficinas de capacitação sobre consciência social, saúde, higiene, nutrição, etc. O relatório aborda ainda a parcela das crianças que são exploradas nas ruas dos centros urbanos. Em todos esses relatos, o tema da participação oscila entre iniciativas que enfatizam mais a proteção e o assistencialismo ofertado às crianças por meio de oficinas informativas e outras que de fato materializam a participação das crianças em projetos sociais, nos quais elas são as principais protagonistas. Embora o relatório aponte a participação das crianças em seus contextos locais, predomina uma visão "adultocêntrica" e assistencialista, apesar de apresentar uma preocupação com a voz das crianças, sobretudo aquelas em situação de vulnerabilidade social.

Assim, a participação infantil é tematizada reiteradas vezes como uma obrigação dos adultos em fazer aflorar e considerar as opiniões das crianças e dos jovens, induzindo-os a manifestar suas opiniões. Essa participação ocorre em variados níveis, desde a interação das crianças com as organizações que promovem a inclusão social, juntamente com os órgãos competentes, seja no âmbito local, seja nacional, seja internacional, abrindo espaços para que as crianças possam dialogar e opinar, até a participação em pequena escala, nas famílias e/ou nas escolas.

De modo geral, tem-se a impressão de que o relatório se preocupa mais em divulgar as ações benéficas do UNICEF do que propriamente trazer uma reflexão sobre o protagonismo e a participação ativa das crianças nas mudanças sociais e políticas que lhes afetam. Essa reflexão aparece de modo mais consistente no próximo relatório, talvez pelo próprio amadurecimento teórico dos debates internacionais, sociológicos e jurídicos sobre o tema, a partir de 2009.

\section{UNICEF: SITUAÇÃO MUNDIAL DA INFÂNCIA: CELEBRANDO OS 20 ANOS DA CONVENÇÃO, EDIÇÃO ESPECIAL (2009)}

Esse relatório trata especialmente dos 20 anos da Convenção sobre os Direitos da Criança, em um mundo cada vez mais populoso, urbanizado e ambientalmente ameaçado. A Convenção assume o desafio de somar a participação social, institucional e individual à responsabilidade governamental pelos direitos da criança, 
em um cenário onde mudanças climáticas e econômicas ameaçam os progressos em relação aos direitos das crianças.

Como se trata de uma edição especial resumindo todos os aspectos da Convenção, não há especificidade sobre nenhum caso de participação, tendo sido tratado de forma geral, abrangendo a participação como um direito garantido pela Convenção, devendo todos os Estados-membros apoiarem a participação de todas as crianças e todos os adolescentes, sem distinção de natureza nenhuma. O relatório resume os aspectos da Convenção e abrange a participação como um direito garantido por ela, porém é preciso ajustar as condições de acordo com sua idade e maturidade. Um exemplo trazido é o de uma estudante de 13 anos, do Vietnã, que, juntamente com seus amigos, faz parte de um grupo de capacitação nas áreas de direitos das crianças, saúde e HIV oferecidos pela escola. Outro exemplo de participação trazido no relatório foi registrado na cidade brasileira de Barra Mansa, que, de 1997 a 2000, manteve um conselho orçamentário participativo que incluía 36 crianças, de diferentes idades, sem especificar a etnia e o sexo. Destaca-se também a Sessão Especial sobre a Criança na Assembleia Geral da ONU, em 2002, que estimulou ativamente a participação de mais de 400 crianças de 150 países. O relatório UniceF (2009, p. 34) também destaca:

O Estudo sobre Violência contra a Criança, produzido em 2002 pelo Secretário-Geral da ONU, foi o primeiro estudo das Nações Unidas a consultar as crianças, refletindo e incorporando suas opiniões e recomendações. Crianças e adolescentes participaram de consultas nos níveis nacionais, regionais e internacionais, ao lado de formuladores de políticas. Para divulgar as constatações do estudo, foram criadas versões em linguagem acessível às crianças, adequadas para diferentes grupos etários. Crianças e adolescentes também tiveram participação significativa no III Congresso Mundial de Enfrentamento da Exploração Sexual de Crianças e Adolescentes, realizado no Rio de Janeiro (Brasil) em novembro de 2008.

O conceito de participação no relatório envolve o "aumento do poder e a capacidade das crianças para que se envolvam em decisões e ações que as afetam", em que se examinam diversas questões relativas ao direito de informação, de manifestação, de liberdade de expressão, etc. (UNICEF, 2009, p. 15). O relatório mostra que, na maioria das vezes, as decisões públicas que afetam as crianças não consideram sua opinião nem as envolvem nos processos, cenário esse que as iniciativas do UNICEF tentam reverter nos países onde atua. 
A participação social da criança é discutida em um contexto em que as políticas não são somente centradas na assistência, tratando as crianças como recebedores passivos de cuidados e serviços, mas sim como atores públicos. Como exemplo de participação da criança como ator público, o relatório fala sobre o projeto Cidades Amigas da Criança (UNicEF, 2009, p. 31):

[...] uma iniciativa internacional que promove a participação da criança nos governos locais. Uma "cidade amiga da criança” é definida como qualquer sistema local de governança - urbano ou rural, amplo ou restrito - comprometido com a realização dos direitos da criança nos termos da Convenção. A Iniciativa Internacional Cidades Amigas da Criança (CFCI) foi lançada em 1996 para promover a resolução aprovada na segunda Conferência das Nações Unidas para os Assentamentos Humanos (Habitat II), que transforma as cidades em locais habitáveis por todos. A conferência declarou que o bem-estar da criança é o principal indicador de um habitat saudável, de uma sociedade democrática e de boa governança.

Conforme visto com Raquel Rei, os espaços de participação social infantil devem cumprir determinadas condições para que eles sejam efetivos, mas, no relatório de 2009 (UNICEF, 2009, p. 34), não há certo otimismo:

Em geral, as crianças não são vistas como atores sociais e políticos. [...] na maioria das vezes, as crianças não têm um lugar formal à mesa de tomada de decisões, e suas opiniões normalmente são representadas por meio de mecanismos controlados por adultos. [...] Em conferências, os adultos podem ouvir as crianças, mas, no momento de tomar decisões importantes, elas frequentemente são excluídas. Parlamentos de jovens acabam sendo pouco mais do que clubes de debate, nos quais as crianças aprendem sobre governança e política. Além disso, algumas tentativas de envolvimento de jovens são simbólicas - servem mais para dar uma ideia de que a organização de adultos os envolve do que para benefício das próprias crianças (grifo nosso).

Após seis anos em relação ao último relatório, percebe-se o esforço em preencher as lacunas teóricas e práticas acerca da participação infantil que supere a cultura "adultocêntrica" nas organizações internacionais, como aqui demonstrado. Embora os relatórios não revelem um cenário otimista, é possível perceber movimentos políticos e sociais mais promissores e também que tende a crescer 
"o número de crianças e adolescentes que vêm desenvolvendo sua capacidade de participar e colaborar por meio de organizações de jovens e de redes de defesa de seus direitos" (UNICEF, 2009, p. 34).

Em relação às condições de gênero, classe, geração e raça, os relatórios contemplaram como as diferenças constituem a criação das diversas infâncias e como elas interpretam o mundo e são por ele interpretadas. A UNICEF sempre teve a política voltada para os direitos humanos na infância e no cumprimento das Metas do Milênio, portanto, as discussões de gênero, classe, geração e raça transparecem como preocupação presente ${ }^{19}$.

De modo geral, é possível responder afirmativamente à questão proposta para essa pesquisa, pois tanto os documentos como os relatórios apontaram para a necessidade de não apenas incentivar e organizar, mas implementar as culturas infantis participativas, percebendo nelas não apenas uma cultura de não adultos, ou de não jovens, mas uma cultura própria que tenha suas próprias demandas, reivindicações, além de poder de fala.

\section{CONSIDERAÇÕES FINAIS}

O revisionismo da SI sobre a teoria da socialização tem auxiliado na problematização de três aspectos principais dessa teoria, das quais as RI podem se apropriar: 1) a visão passiva da criança, cuja socialização é regida por instituições e pelos adultos; 2) os estudos centrados exclusivamente na criança enquanto aluno/a ou na criança-problema (infrator); e 3) a hegemonia do discurso "adultocêntrico" nas pesquisas com crianças. Analisou-se que a SI colabora na superação da própria sociologia como ciência "adultocêntrica", desatenta ao universo infantil e às crianças como sujeitos ativos, cujos pontos de vista eram ignorados ou secundarizados nas pesquisas. Essa é a principal lição que os estudos em RI devem aprender com a SI - superar a visão "adultocêntrica” nas pesquisas em RI implica estar

19 Ao contrário do relatório de 2003, em 2009 aparece o conceito de gênero no seguinte trecho: "Em 2007, as meninas eram maioria entre os 101 milhões de crianças em idade escolar que não frequentavam a escola primária. Nesse nível de educação, as diferenças de gênero mais acentuadas estão na África Central e Ocidental, no Oriente Médio e Norte da África e na Ásia Meridional. Meninas de famílias pobres e que vivem em áreas rurais correm sério risco de ficar sem educação primária e secundária. Diferenças de gênero no acesso a cuidados de saúde também são visíveis em alguns países da Ásia Meridional e da África ao sul do Saara. Além de ser uma violação de normas e leis, o casamento infantil, que na maioria dos casos envolve meninas, aumenta o risco de privá-las da educação e de torná-las mães ainda na adolescência, com os consequentes riscos de saúde para a mãe e para a criança. Na África Oriental e Meridional, mulheres jovens continuam desproporcionalmente vulneráveis à infecção por HIV: a probabilidade de meninas adolescentes viverem com HIV é de duas a 4,5 vezes maior do que a dos meninos" (UNICEF, 2009, p. 15). 
atento ao universo infantil, seja aquele retratado pelos documentos, relatórios e fatos internacionais aqui apresentados, seja tudo o que se refira à infância no cenário internacional. Trata-se da infância urbana ou rural, pobre ou rica, letrada ou analfabeta.

Essa problematização sugere uma compreensão mais ampla da criança como ator social, como aquela que participa, a seu modo, de sua própria socialização, que não se restringe ao único papel de estudante ou de criança-problema e, ainda, como aquela que pode ser tratada como interlocutor principal, e não apenas mero respondente ou informante. Pela análise empreendida, ficou claro que ainda é preciso trilhar um longo caminho para reconhecer a criança para além desses papéis.

A questão norteadora foi respondida nesta análise mostrando que é possível falar em uma participação social e política das crianças no cenário de forte globalização, apesar de ainda predominar uma cultura juvenil e "adultocêntrica", inclusive na própria redação dos ensaios que compõem os relatórios. Nenhum deles foi escrito por uma criança; apenas elas são ouvidas na forma de depoimentos. A redação ainda é privilégio dos adultos.

Atualmente, há um debate público em relação às crianças e a seu status na sociedade e como membros dela. Um dos pilares da ONU sobre os direitos das crianças é justamente relacionado ao direito de participação. Dar ouvidos à criança e suas opiniões tem sido um desafio por parte dos órgãos competentes, assim, no ano de 2003, a UNICEF lançou um relatório sobre a situação mundial da infância que teve como foco a participação infantil e demonstrou a importância de considerar as opiniões das crianças e dos jovens com seriedade, bem como a responsabilidade dos adultos em ajudá-las a desenvolver suas competências para que tenham uma participação autêntica e significativa no mundo. Todavia, o relatório de 2009 mostrou que ainda é necessário avançar na compreensão política e social do que implica essa participação, das questões orçamentárias, culturais e políticas que envolvem esse nível de cidadania. Torna-se imprescindível que os conhecimentos produzidos pelas ciências humanas e sociais sejam tomados de forma dialética, que vejam a criança não só a partir do referencial do adulto, mas também a partir dela mesma, ou seja, de sua experiência de infância, seja ela relatada de memória (rememoração) ou no tempo presente, do imediatamente vivido, mediante uma análise de sua participação.

Cumpre ressaltar que o objetivo aqui não foi defender uma "tirania da voz infantil" ou sequer ignorar que essa voz também pode ser manipuladora e inventiva, mas defender o reconhecimento social e jurídico da capacidade de participação das 
crianças, em uma cultura social e jurídica que forme indivíduos que possam decidir, por eles mesmos, essa participação (afinal, participa quem quer). Ora, como gerar esse reconhecimento se muitas vezes sequer vemos as crianças? Onde elas estão? Nas ruas, nas escolas, nas audiências? Como estão construindo suas infâncias e lutando contra toda a forma de opressão? Que espaços de participação elas possuem para exercer seus "direitos da autonomia"? Também defende-se a superação de uma visão tradicional e "adultocêntrica" que, ao idealizar uma infância, perde de vista sua pluralidade e a própria noção de uma infância ainda em construção, de uma infância do devir, e não de uma infância perdida no passado.

Diferentes infâncias, diferentes crianças, diferentes teorias contribuem não só para o amadurecimento teórico e empírico da sociologia e das Relações Internacionais no trato com a infância, mas, sobretudo, no fortalecimento dos espaços institucionais e não institucionais de participação infantil.

\section{REFERÊNCIAS BIBLIOGRÁFICAS}

Christensen, Pia; Allison, James (Org.). Investigação com crianças: perspectivas e práticas. Porto: Paula Frassinetti, 2005.

DurкheIm, Emile. As formas elementares da vida religiosa. In: Aron, Raymond. As etapas do pensamento sociológico. São Paulo: Ed. Martins Fontes, 2002.

FonseCA, Claudia. Os direitos da criança - dialogando com o ECA. In: FonseCA, Claudia; Terto JR., Veriano; Alves, Caleb Faria (Org.). Antropologia, diversidade e direitos humanos. RGS: Ed. UFRG, 2004.

Gaitán, L. Sociologia de la infância. Madrid: Síntesis, 2006.

KuHLMANN JR., Moisés. As grandes festas didáticas: a educação brasileira e as exposições internacionais (1862-1922). Bragança Paulista: Ed. da Universidade de São Francisco, 2001.

Nunes, Angela; Carvalho, Maria Rosário. Questões metodológicas e epistemológicas suscitadas pela Antropologia da Infância. In: Encontro Anual da Anpocs, 32. Apresentação... 22 a 26 de outubro de 2008, Caxambu/MG.

Pecequilo, Cristina Soreanu. Os atores internacionais. Introdução às Relações Internacionais: temas, atores e visões. Petrópolis, RJ: Vozes, 2004.

Prout, Allan. Reconsiderar a nova Sociologia da Infância. In: Encontro Anual DA Secção de Sociologia da Infância, da Associação Alemã de Sociologia, 8. Apresentação... Minho, 2002. In: Ciclo de ConfERÊNCIAS EM SI dA Univ. do Minho/IEC. Minho, 2004.

Qvortrup, Jens. Macro-análise da infância. In: Christensen, Pia; Allison, James (Org.). Investigação com crianças: perspectivas e práticas. Porto: Paula Frassinetti, 2005. 
REI, Raquel C. Teixeira. Participação social da infância. Barcelona: Ed. UAB, 2006.

SAто, Eiiti. As relações internacionais, a sociologia e os debates correntes sobre conflito, cooperação e mudanças na ordem internacional. 2005. Disponível em: <http://www. cedep.ifch.ufrgs.br/Textos_Elet/Alas/Eiiti\%20Sato.pdf >. Acesso em: 26/o2/2012.

Sarmento, M. J.; Pinto, Manuel. As crianças: contextos e identidades. Braga:/IEC-Univ. Minho, Pt, 1997.

. As culturas da infância nas encruzilhadas da $2^{\mathrm{a}}$ modernidade. In: SARMENTo,

M. J.; Cerisara, A. B. (Org.). Crianças e miúdos: perspectivas sócio-pedagógicas da infância e educação. Porto: Asa, 2004. p. 9-34.

Gerações e alteridade: interrogações a partir da sociologia da infância. Educação e Sociedade. Dossiê: Sociologia da Infância - pesquisa com crianças. CEDES, v. 26, n. 91, maio/ago. 2005.

Sirota, Régine. Emergência de uma Sociologia da Infância: evolução do objeto e do olhar. Cadernos de Pesquisa, n. 112, mar. 2001.

SOARES, Natália F. Os direitos das crianças nas encruzilhadas da protecção e da participação (2002). In: Infoced. Boletim do Centro de Estudos, Documentação e Informação sobre a Criança do Instituto de Apoio à Criança. Lisboa: IAC, maio 2010.

\section{SITES}

AgÊncia Envolverde. Crianças aprisionadas no coração do levante. Disponível em: < http:// envolverde.com.br/ips/inter-press-service-reportagens/criancas-aprisionadas-nocoracao-do-levante-2/>. Acesso em: 01/05/2012.

BRASIl. Decreto n. 3.413, de 14 de abril de 2000. Convenção da Haia sobre os aspectos civis do seqüestro internacional de crianças. Disponível em: <http://www.planalto. gov.br/ccivil_03/decreto/D3413.htm>. Acesso em: 23/03/2012.

Deutsche Welle. Tráfico de crianças é problema global. Disponível em: <http://www. dw.de/dw/article/o,,1036172,0o.html>. Acesso em: 23/03/2012.

GreEn, Andrew. Como devolver a infância às crianças-soldado. Disponível em: <http:// envolverde.com.br/noticias/como-devolver-a-infancia-as-criancas-soldado/>. Acesso em: 01/05/2012.

Hartmann, Arturo. Oriente Médio: infância entre grades. Disponível em: <http://ponto. outraspalavras.net/2011/10/25/infancia-entre-grades-criancas-palestinas-sao-alvode-tortura-detencoes-ilegais-em-israel/>. Acesso em: 26/10/2011.

Nobrega, Camila. Severn Suzuki, a menina que calou o mundo na Rio 92. Disponível em: <http://oglobo.globo.com/rio2o/severn-suzuki-menina-que-calou-mundona-rio-92-4638046>. Acesso em: 01/05/2012. 
SAVE the children. Agenda de infância 2012-2015. Disponível em: <http://www. savethechildren.es/docs/Ficheros/465/Agenda_de_Infancia_2012-2015.pdf>. Acesso em: 05/06/2012.

SATo, Eiti. A agenda internacional depois da Guerra Fria: novos temas e novas percepções. Rev. Bras. Polít. Int., v. 43, n. 1, p. 138-169, 2000. Disponível em: <http://www.scielo. br/pdf/rbpi/v43n1/v43n1a07.pdf>. Acesso em: 26/o2/2012.

The DCI Movement. Disponível em: <http://www.defenceforchildren.org/about-us.html>. Acesso em: 30/04/2012.

The Global Journal. Free the children. Disponível em: <http://theglobaljournal.net/article/ view/564/>. Acesso em: 30/04/2012.

The Global Journal. Friends international. Disponível em: < http://theglobaljournal.net/ article/view/557/>. Acesso em: 30/04/2012.

UnicEF. Relatórios. Disponível em: <http://www.unicef.org/brazil/pt/resources_9478. htm>. Acesso em: 02/2011.

. Situação mundial da infância 2003: participação infantil. Disponível em: <http://www.unicef.org/brazil/pt/resources_10341.htm>. Acesso em: 02/11/2011.

. Situação mundial da infância 20o8: caderno Brasil. Disponível em: <http:// www.unicef.org/brazil/pt/cadernobrasil2008.pdf>. Acesso em: 02/11/2012.

. Situação mundial da infância 2009 (edição especial): celebrando 20 anos da Convenção sobre os Direitos da Criança. Disponível em: <http://www.unicef.org/ brazil/pt/sowc_20anosCDC.pdf >. Acesso em: 02/06/2011.

VEJA. Caso Sean Goldman: garoto fala pela $1^{\mathrm{a}}$ vez à TV nos EUA. Disponível em: <http:// veja.abril.com.br/noticia/internacional/caso-sean-goldman-garoto-fala-pela-1a-veza-tv-americana>. Acesso em: 01/05/2012.

Recebido para publicação em 14/08/12. Aceito para publicação em 15/04/13. 